\title{
Ensino da Didática no curso de licenciatura em pedagogia
}

Joana Paulin Romanowski

Centro Universitário Internacional e Pontifícia Universidade Católica do Paraná (Brasil)

Juliana Domit Mallat

Enderson Lopes Guimarães

Pontifícia Universidade Católica do Paraná (Brasil)

\section{Resumo}

O artigo focaliza o ensino de Didática a partir da análise das ementas dessa disciplina, de 1970 a 2018, no curso de licenciatura em pedagogia. Compreende a Didática como área do conhecimento que expressa a relação teórica e prática no processo de ensino e aprendizagem. Analisa a relação entre os diferentes períodos da formação de professores e o ensino de Didática. Para isso, realiza uma pesquisa de abordagem qualitativa (LUDKE; ANDRÉ, 2013), alicerçada em estudo documental e bibliográfico. Os aportes de estudo incluem Gatti, Martins, Romanowski, Veiga, e outros autores que discutem a Didática no contexto das políticas educacionais e da formação de professores. Os dados indicam que o ensino de Didática expressa mudanças de abordagens determinadas pela organização social e política, das pesquisas e da prática pedagógica, o que influencia seu ensino e resulta um conhecimento poderoso na formação dos professores.

Palavras-chave: Ensino de Didática. Curso de pedagogia. Abordagens pedagógicas. Formação do pedagogo.

\section{Teaching of Didactics in the bachelor's degree in pedagogy}

\section{Abstract}

The article focuses on the teaching of didactics from the analysis of the course menus from the 1970 to 2018 in a bachelor's degree in pedagogy. It comprises didactics as an area of knowledge that expresses the theoretical and practical relationship in the teaching and learning process. It analyzes the relationship between the different periods of teacher formation and the teaching of didactics. For this, it conducts a qualitative approach research (LUDKE; ANDRÉ, 2013 ) based on documentary and bibliographical study. The contributions include Gatti, Martins, Romanowski, Veiga, and others authors who discuss didactics in the context of educational policies and teacher formation. The data indicate that the teaching of didactics express changes in approaches determined by social and political organization, research and pedagogical practice, which influences their teaching and results in a powerful knowledge in teacher formation.

Keywords: Teaching of didactics. Pedagogy course. Pedagogical approaches. Pedagogue formation. 
Ensino da Didática no curso de licenciatura em pedagogia

\section{Enseñanza de la Didáctica en el curso de licenciatura en pedagogía}

\section{Resumen}

El artículo se centra en la enseñanza de la didáctica a partir del análisis de los menús de esa disciplina, de 1970 a 2018 , en un curso de licenciatura en pedagogía. Comprende la didáctica como un área de conocimiento que expresa la relación teórica y práctica en el proceso de enseñanza y aprendizaje. Analiza la relación entre los diferentes períodos de formación de los profesores y la enseñanza de la didáctica. Para ello, realiza una investigación de enfoque cualitativo (LUDKE; ANDRÉ, 2013) basada en el estudio documental y bibliográfico. Las contribuciones incluyen a Gatti, Martins, Romanowski, Veiga y otros autores que discuten la didáctica en el contexto de las políticas educativas y la formación de los profesores. Los datos indican que la enseñanza de la didáctica expresa cambios en los enfoques determinados por la organización social y política, la investigación y la práctica pedagógica, lo que influye en su enseñanza y da como resultado un poderoso conocimiento en la formación de los profesores. Palabras clave: Enseñanza de la didáctica. Curso de pedagogía. Enfoques pedagógicos. Formación de pedagogos.

\section{Introdução}

A formação inicial de professores em nível superior, a partir da criação dos cursos de licenciatura na década de 1930, constitui-se um campo de estudos no Brasil na perspectiva da formação básica dos professores. Pesquisas na área da educação indicam uma preocupação com essa formação ao examinar os cursos de licenciatura como responsáveis pela formação de professores para a educação básica (GATTI, 2010).

Nesta perspectiva, apresentamos elementos indicadores da inserção da Didática no curso de Pedagogia, a partir do histórico desse curso de licenciatura. Ao eleger o exame da Didática, compreendemos essa disciplina como basilar por ser seu objeto de estudo o processo de ensino e aprendizagem e, consequentemente, a docência (CRUZ, 2017), eixo central dos cursos de formação inicial de professores (MARCELO, 1999; ROMANOWSKI, 20 16).

No bojo do histórico do curso de Pedagogia e do ensino da Didática, objetivamos apresentar as relações empreendidas entre as políticas para a formação inicial de professores e as perspectivas do ensino de Didática ao longo dos anos e implicações do programa de ensino expresso na ementa dessa disciplina, ou seja, a relação entre as políticas, a teoria e a prática no ensino da Didática. 
Para compreender melhor essas relações, a investigação desenvolvida, de natureza qualitativa, segundo Lüdke e André (1986, p. 13) "[...] envolve a obtenção de dados descritivos, obtidos no contato direto do pesquisador com a situação estudada, enfatiza mais o processo do que o produto." Oestudo é documental, a partir das Diretrizes de Formação de Professores (BRASIL, 2002, 2006 e 2015), das políticas educacionais (GATTI, 2009) e dos planos de ensino da disciplina de Didática de um curso de licenciatura em Pedagogia de uma universidade pública do estado do Paraná e também em referenciais do campo. $\bigcirc$ exame dos dados é baseado na análise da ementa quanto aos itens de conhecimentos entendidos como conteúdos de ensino.

$\bigcirc$ estudo foi realizado com consulta nas ementas da disciplina de Didática, a partir dos planos de ensino disponíveis no setor de educação da Universidade Federal do Paraná. Foram localizados os planos de ensino desde os anos de 1970. Utilizamos a Análise de conteúdo (BARDIN, 2011 ) como metodologia de pesquisa para a sistematização e análise dos dados levantados. Umas das técnicas da análise de conteúdo que utilizaremos é o teste por associação de palavras, que Bardin (201 1) relata ser o mais antigo dos testes projetivos, compreendendo que este teste é utilizado na Análise de Conteúdo para fazer surgir espontaneamente associações relativas às palavras exploradas ao nível dos estereótipos que criam. As diferentes fases da Análise de Conteúdo organizam-se em torno de três polos, conforme Bardin (201 1, p. $125)$ "[...] a pré-análise; a exploração do material; e, por fim, o tratamento dos resultados: a inferência e a interpretação".

A partir deste movimento contínuo de análise e síntese, comparando, constantemente, as unidades de significado e relacionando os dados coletados, foram estabelecidas as categorias, tendo como orientação a análise de conteúdo de Bardin (201 1), tendo em vista o problema dessa investigação.

artigo está organizado do seguinte modo: na primeira seção, são apresentados os elementos do histórico da formação de professores no Brasil e as relações com o ensino de Didática neste contexto. Na segunda seção, é feita a análise da trajetória da constituição da disciplina de Didática em um curso de Licenciatura de uma Universidade pública do Paraná. Por fim, os objetivos são retomados nas considerações. 


\section{Os cursos de licenciatura e o ensino da Didática diante das políticas de formação de professores}

Os cursos de formação de professores em nível superior no Brasil, começaram a se delinear a partir da década de 1930, por meio do movimento dos Pioneiros da Escola Nova que afirmava que, até aquele momento, o ensino superior estava apenas a serviço das profissões ditas liberais, que atendiam à engenharia, à medicina e ao direito (MACHADO; TERUYA, 2007). Nessa perspectiva elitizada, não havia espaço para a formação de professores, bastava a estes o ensino secundário de cultura geral, como previa a Reforma Francisco Campos e o ideário dos Pioneiros que anunciava a necessidade de formação universitária aos docentes (AZEVEDO, 1932).

Assim, nos anos de 1930, tem-se a organização da primeira universidade, a Faculdade de Filosofia, Ciências e Letras da Universidade de São Paulo. Essa Faculdade concebia uma formação de professores para lecionar nos cursos secundários e com características de uma universidade moderna: ensino, pesquisa e extensão, tornando-se, segundo Saviani (2009), referência para as demais instituições de nível superior. No âmbito político legal, em 1939, o Decreto-Lei n 1. 190, de 4 de abril de 1939 foi estendido para todo o país e compôs o modelo de formação instituído como "esquema 3+1", adotado na organização dos cursos de licenciatura e de Pedagogia. $\bigcirc$ Decreto-Lei teve como objetivo principal a formação para cursos secundários, dividindo-se em 3 anos para a formação específica e mais um ano para a formação pedagógica/didática, estabelecendo uma formação genérica, impregnada de transmissão da cultura geral (VEIGA, 1994).

A Didática é assim compreendida enquanto um conjunto de regras e normas, que "[...] visa à orientação técnica do ensino e do estudo [...]" (VEIGA, 1994, p. 41), determinando a ordem, o ritmo, buscando disseminar uma visão burguesa do mundo. Como efeito, desvinculava do contexto social e da formação política dos estudantes, baseava-se no pragmatismo (MARTINS; DUARTE, 20 10), sobretudo da Psicologia Evolutiva e da Aprendizagem, apontando o aprender a aprender e o aprender a fazer como pilares centrais no processo de ensino-aprendizagem, num processo de valorização do conhecimento psicológico sobre o social.

Na década de 1960, ano em que se desenvolveram as lutas para ampliação do acesso à educação pública, resultando na primeira Lei e 
Diretrizes e Bases da Educação Nacional (Lei n 4.024, de 20 de dezembro de 1961 (BRASIL, 1961), determinando que a formação de docentes para o ensino primário seria realizada em escolas normais de grau colegial, com, no mínimo, três séries anuais, sendo ministrada a formação pedagógica. A formação para o professor para as disciplinas específicas do secundário e do ensino médio seria feita nas faculdades de Filosofia, Ciências e Letras. Sob a vigência do Parecer 262/62 (BRASIL, 1962) regulamentou-se os currículos mínimos aos cursos de licenciatura de matérias de bacharelado e processos pedagógicos, o que mantinha a fórmula $3+1$.

Em meados de 1964, o regime militar reposicionou a educação, a sociedade e as políticas públicas, expandindo o processo de industrialização, renovação de serviços e capital privado. A combinação desses fatores foi denominada milagre econômico e, consequentemente, contribuiu para a ampliação das escolas e do ensino superior. Conjugada aos fatores da demanda da população, às novas exigências do modelo econômico que se legitimava com o regime militar. Segundo Sauthier e Junges (2016), o governo realizou acordos com os Estados Unidos, em que foram oferecidos recursos financeiros e assistência técnica para a pressuposta reforma educacional (MEC/USAID I.

Nesse período, a Didática estruturava-se em uma disciplina normativa, a partir da neutralidade científica, desenvolvendo-se por meio de técnicas e orientações, estando no centro o planejamento e o controle como garantia da produtividade. Os conteúdos dos cursos de Didática "[...] centravam-se na organização racional do processo de ensino, isto é, no planejamento didático formal e na elaboração de materiais instrucionais" (VEIGA, 2004, p. 24). Nessa perspectiva, Rosa (1989, p. 32) destaca que "os cursos de Didática se constituem, basicamente, em cursos sobre planejamento de ensino, cuja abordagem corresponde à própria operacionalização do sistema".

Nesse contexto desenvolvimentista, foi promulgada a Lei n ${ }^{\circ}$ 5.692/71 (BRASIL, 1971), que definia a reforma da educação básica brasileira, transformando as escolas normais em habilitação dos cursos de Magistério. Esse modelo, sustentou-se sob uma lógica tecnicista, na formação de um professor tecnicamente competente (MARTINS, 2009), ou seja, um bom executor de tarefas, que promovesse um ensino eficaz e eficiente. Segundo Gatti (2009), a formação de professores foi permeada por um currículo disperso, neutro, recaindo as preocupações sobre a modernização da prática por meio de métodos e técnicas, com uma formação esvaziada, sustentada sobre a força 
Ensino da Didática no curso de licenciatura em pedagogia

produtiva de servir ao capital. Pereira (1999) destaca a valorização do domínio da área do conhecimento específico do que se vai ensinar, destacada nas propostas dos cursos de formação de professores.

Em 1972, foi realizado o I Encontro Nacional de Professores de Didática, um movimento contraditório às políticas liberais e autoritárias, resultando na formulação de um documento intitulado de "Redefinição da Didática" (MARTINS, 1998), que ressalta a necessidade de compreensão de novas relações sociais e rupturas com as relações estabelecidas no regime militar. $\bigcirc$ documento se constitui germe de resistência.

Mais ao final desta década, acentuaram-se as discussões acerca da importância da dimensão política para o ensino, até então silenciada pela perspectiva instrumental fundada na neutralidade técnica (CANDAU, 1984). Foi na década de 1980 que se instalou a Nova República, iniciando um movimento de ascensão do governo civil e da luta operária, fortalecendo as inquietações e insatisfações dos educadores que compreendem a educação como prática social, vinculada a um projeto histórico (GATTI, 2009). Assim, na década de 1980 se iniciam tentativas de rompimento com o pensamento tecnicista, buscando avanços no sentido de uma educação emancipatória (FREITAS, 62002 ). A sociedade em expansão trazia novas necessidades, que iam além da formação técnica, oportunizando o repensar de um novo profissional.

Nessa conjuntura, em 1982 efetivou-se o segundo encontro "A Didática em Questão", de forma que a preocupação girava em torno de um professor politicamente comprometido com a transformação social IMARTINS, 20121, buscando compreender a relação entre a prática escolar e a estrutura social mais ampla, por meio da relação entre uma Didática pensada e uma Didática vivida (MARTINS, 1998). O contexto marcou um período de revisão crítica e reconstrução da Didática, um momento especial de produção intelectual e de ruptura com paradigmas fortemente instaurados no cenário político e educacional daquele regime.

Neste mesmo ano foi aprovada a Lei n 7.044 , de 18 de outubro de 1982 (BRASIL, 1982), que alterou o artigo 30 da Lei n 5.692/71 (BRASIL, 1971), alterando as propostas de formação na Habilitação Magistério, restringindo a atuação de $1^{a}$ a $4^{a}$ série. Altera também a atuação das licenciaturas curtas formando docentes para trabalhar da $5^{a}$ até $8^{a}$ série, mas também de $1^{a}$ a $4^{a}$ série, e a licenciatura plena para atuação em toda a educação de $1^{\circ}$ 
e $2^{\circ}$ graus, conforme Gatti (2009), a licenciatura curta foi mantida, ainda que alterada.

A promulgação da Constituição Federal, em 1988, contribuiu para que a década de 1990 representasse um relevante marco na educação brasileira, especialmente a configuração da formação de professores, com a profusão de pareceres, diretrizes, parâmetros e resoluções promulgadas pelo Ministério da Educação. Naquela conjuntura, se definiram novos rumos para a educação brasileira, mas sustentados no capitalismo, cujo projeto educacional baseia-se numa economia de mercado e no acesso às instituições privadas, especialmente em nível superior. A promulgação da LDBEN (BRASIL, 1996), mesmo com avanços, continua contribuindo para a privatização do ensino. Contraditoriamente, essa expansão pode ter favorecido a elevação da titulação dos professores da educação básica, pois, em 1966, a formação em nível superior na educação infantil era de cerca de $17 \%,-18,5 \%$ nos anos iniciais do ensino fundamental, $68 \%$ nos anos finais e $74,3 \%$ no ensino médio. Os dados de 2018 indicam que a titulação em ensino superior dos professores é de $68,4 \%$ na educação infantil, 77,3\% no ensino fundamental anos iniciais, $84,3 \%$ no ensino fundamental anos finais e $88,6 \%$ no ensino médio (INEP, 2018).

A promulgação da LDBEN (BRASIL, 1996), impulsionou o debate acerca da formação de professores, definindo a necessidade de instituição de diretrizes e demais legislações específicas a essa formação. Esse momento foi permeado pelo acirramento de uma Didática crítica, ao mesmo tempo em que houve a ampliação das políticas neoliberais na educação, influenciando contradições na organização do processo de ensino-aprendizagem e na formação dos professores.

Em decorrência dos princípios de controle do neoliberalismo, as avaliações externas, resultam na desvalorização da formação pedagógica e na necessidade de uma formação prática e aligeirada, o que impacta as propostas de proposições críticas do campo epistemológico na formação dos professores. Essa lógica contribui para a substituição da Didática geral pelas Didáticas específicas (MARTINS; ROMANOWSKI, 2010) e pelas práticas de ensino, valorizando o conhecimento técnico da disciplina cumprindo, assim, o modelo de formação preconizado pelas políiticas neoliberais, sustentado nos quatro pilares para a educação básica (VEIGA, 2004). 
Ensino da Didática no curso de licenciatura em pedagogia

Nesta perspectiva, há na formação inicial de professores, um embate no ensino da Didática tomado de modo ambíguo, tanto na defesa de uma Didática fundamental como numa Didática instrumental (CRUZ; ANDRÉ, 20121 , em que se concebe relevante a valorização do ato pedagógico, numa perspectiva de educação enquanto prática social, assentada no ensino de uma Didática que valoriza o ato político sob o ato pedagógico, mas também uma Didática assentada nas normas legais que valoriza o fazer pedagógico.

Em meio a este debate, são publicadas, em 2002, as Diretrizes Curriculares Nacionais para a Formação de Professores, por meio do Conselho Nacional de Educação (CNE), que instituem as Diretrizes Curriculares Nacionais para a Formação de Professores da Educação Básica CNE/CP n ${ }^{\circ}$ 1/2002 (BRASIL, 2002) que buscou estabelecer um diálogo com a LDBEN (BRASIL, 1996). Nesse sentido, contemplando as políticas educacionais já materializadas, a concepção de formação de professores recai no ensino por competências, definindo que essa deve considerar o "[...] conjunto das competências necessárias à atuação profissional" (BRASIL, 2002, p. 2).

A partir do momento em que as Diretrizes Curriculares Nacionais para a Formação de Professores (CNE/CP N ${ }^{0}$ 1/2002) foram promulgadas, 8 iniciaram-se as discussões sobre as Diretrizes Curriculares dos cursos de licenciatura que, mesmo sofrendo ajustes, continuaram a anunciar a prevalência de formação por área do conhecimento, com pouco espaço para a formação pedagógica (GATTI, 2009). Adentrou-se o século XXI repetindo-se a formação consolidada no século anterior, que valoriza a formação específica e pouco integra essa formação com a docência ou com a área pedagógica. Todavia, valorizando o modelo operacional, com ênfase nos resultados, sob a perspectiva de uma formação aligeirada do ponto de vista teórico, cede-se lugar à formação prática (SCHEIBE; BAZZO, 2013).

Diante de pareceres, normas e diretrizes, podemos afirmar que há uma descontinuidade nas políticas educacionais referentes à formação de professores, estabelece-se um vai e vem de resoluções que definem, instituem e adiam as políticas educacionais, consequência de inúmeros fatores, entre eles destaca-se "[...] a ausência de uma política de Estado que assuma sua responsabilidade pela formação inicial dos professores com a qualidade requerida pelo mundo contemporâneo" (SCHEIBE; BAZZO, 2013, p. 23).

A formação de professores dos anos 2000, propõe alterações à formação inicial, e provoca movimentos contraditórios em seu desenvolvimento 
e materialização. De um lado uma formação assentada no saber fazer e na valorização dos conhecimentos específicos, ou seja, nos conteúdos a ensinar, atendendo às exigências de uma formação desintegrada e frágil. E, por outro lado, um movimento que valoriza o ensino enquanto prática social, parte de concepções progressistas que gozam da autonomia universitária para uma flexibilização curricular, concebendo o ensino enquanto ato político e pedagógico (MARTINS, 1998).

Somente em 2006 publicam-se as Diretrizes Curriculares Nacionais para o curso de Pedagogia CNE/CP n $01 / 2006$ (BRASIL, 2006), diretriz que aponta uma nova identidade, conferindo à docência como base da formação do curso. As diretrizes justificam a concepção de docência como eixo central na formação de professores compreendendo-a enquanto "[...] ação educativa e processo metódico e intencional [...] desenvolvendo-se na articulação entre conhecimentos científicos e culturais, valores éticos e estéticos e de construção do conhecimento, entre diferentes visões de mundo" (BRASIL, 2006 , p. 1). No documento, docência, destina-se especialmente à formação de professores para os anos iniciais do ensino fundamental e para a educação infantil.

A promulgação da DCN 01 /2006 (BRASIL, 2006) parece indicar em seu bojo, uma relevância ao campo da Didática, geral e específica, uma vez que compreendemos que este campo do conhecimento tem a docência e o ensino como foco principal para a formação do professor. Todavia, acerca desse modelo de organização, as diretrizes indicam três núcleos de estudos: estudos básicos, aprofundamento e diversificação de estudos e estudos integradores para enriquecimento curricular (BRASIL, 2006). Saviani (2008, p. 29) destaca que as diretrizes fazem menção ao estudo "[...] da Didática, de teorias e metodologias pedagógicas, de processos da organização do trabatho docente[...]"; em seguida, faz referência à "[...] decodificação e utilização de códigos de diferentes linguagens utilizadas por crianças, além do trabalho didático com conteúdos, pertinentes aos primeiros anos de escolarização".

Na continuidade da materialização de políticas destinadas à formação de professores, no movimento de avanços, retrocessos e rupturas, em 2015, ocorreu a aprovação das Diretrizes de Formação Inicial e Continuada dos Profissionais do Magistério da Educação Básica (BRASIL, 20 15), desta vez incluído o curso de Pedagogia. Essas diretrizes enfatizam a necessidade de formação pedagógica dos professores nos cursos de licenciatura e reafirmam 
Ensino da Didática no curso de licenciatura em pedagogia

a necessária aproximação entre a universidade e as escolas de educação básica. As afirmações expressas nessa Resolução destacam nuances de que a formação inicial não se limita aos conhecimentos específicos e às técnicas de ensino, o que indica uma ruptura com diretrizes anteriores direcionadas às competências como base do processo formativo com pouca ênfase ao campo da Didática na formação inicial de professores. Discutir as diretrizes 02/2015 (BRASIL, 2015) ainda se constitui desafio no momento político atual, em que há sinalização de políticas para o desmonte do ensino superior. Além disso, essas diretrizes têm sua implementação adiada pela prorrogação do tempo de materialização e mesmo há anúncios de que foi encaminhada em dezembro de 2018 ao Conselho Nacional de Educação uma proposta de Base Nacional Comum para a Formação de Professores da Educação Básica e uma nova proposta está em andamento, gerando um clima de incertezas de continuidade de discussões mais aprofundadas do processo docente, em que se inserem avanços e retrocessos, no atendimento às necessidades da sociedade.

No entanto, a Resolução 02/2015 destaca a necessidade de formação pedagógica dos professores nos cursos de licenciatura, reafirmando a necessária aproximação entre a universidade e as escolas de educação 10 básica. As afirmações destacam nuances de que a formação inicial não se limita aos conhecimentos específicos e às técnicas de ensino, o que indica uma ruptura com diretrizes anteriores que indicavam a competência como base do processo formativo e desvalorizavam o campo da Didática na formação inicial de professores.

Discutir as Diretrizes 02/2015 (BRASIL, 2015) ainda se constitui num desafio no momento político atual, num período de transição de governos, desmonte do ensino superior e pela ampliação do tempo de materialização da própria legislação. Nesse movimento, está a clareza de que a educação e, especialmente, a formação de professores estão sempre inseridas num processo de contradição, avanços e retrocessos, no que toca ao atendimento das necessidades sócio-históricas. É fundamental reafirmar a necessidade de formação pedagógica dos professores nos cursos de licenciatura com a necessária aproximação entre a universidade e as escolas de educação básica.

Para nos aproximarmos desse embate e identificarmos a especificidade da Didática no curso de licenciatura em Pedagogia ao longo da história de formação de professores, optamos, após essa contextualização assentada em referenciais, examinar como se materializou a disciplina de Didática Geral 
na primeira universidade do estado do Paraná a ofertar esse curso. A disciplina de Didática Geral torna-se basilar por expressar a concepção de aprendizagem no interior da formação de professores, influenciada pelo modo como está organizada a sociedade, a política, a economia e a própria escola. Todavia, situada historicamente e expressando na prática as relações e tensões ao longo da constituição das políticas educacionais.

\section{O curso de licenciatura em Pedagogia na Universidade Federal do Paraná}

A Universidade do Paraná foi criada em 1912, mas só foi federalizada e enominada como Universidade Federal do Paraná em 1950. Em 1938, foi criada a Faculdade de Filosofia, Ciências e Letras, que, no ano de 1939, passou a contar com o Departamento de Pedagogia (Pedagogia e Didática), sendo reconhecido o curso pelo Governo Federal no ano de 1940, formando Licenciados e Bacharéis, mas somente em 1946 é integrada a Universidade do Paraná. No início de 1961, o Departamento de Pedagogia passou a ofertar os cursos de Pedagogia, de Didática e de Orientação Educacional. Em 1975, foi aprovado o currículo que instituiu as habilitações Supervisão Escolar, Orientação Educacional, Administração Escolar, mais a formação para o Magistério das disciplinas pedagógicas do $2^{\circ}$ grau (GONÇALVES; VIEIRA, $2016)$. Posteriormente, em 1994, foi encaminhada uma proposta de reformulação do currículo do Curso de Pedagogia da UFPR, aprovada em 1996, com foco na formação para a docência. Uma nova reformulação para o currículo do curso de Pedagogia presencial foi aprovada em 2007 e, em 2009, foi criado o curso de Pedagogia a distância.

As diretrizes, aprovadas em 2006, ecoam a discussão acerca do pedagogo unitário, que indicam a finalização da oferta das habilitações no curso de Pedagogia e expande o tempo de formação de quatro para cinco anos (GONÇALVES; VIEIRA 2016). Nessa perspectiva, o curso contempla 2.800 horas de disciplinas obrigatórias, 300 horas de optativas e 100 horas de atividades formativas. Segundo Gonçalves e Vieira (2016, p. 16) "[...] essas mudanças decorreram da tentativa de contemplar as diversas funções correspondentes à concepção de pedagogo unitário, presentes na múltipla embora única - habilitação". 
A seguir apresentamos o quadro com os conteúdos da disciplina de Didática na UFPR sistematizados por ano de 1972 a 2018.

Quadro I - Síntese dos conteúdos listados nos planos de ensino de Didática

\begin{tabular}{|c|c|c|c|}
\hline \multirow{8}{*}{ 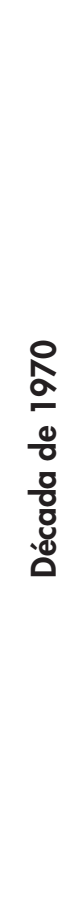 } & 1972 & 1975 & 1978 \\
\hline & $\begin{array}{c}\text { Inteligência e adaptação } \\
\text { biológica }\end{array}$ & \multirow{2}{*}{$\begin{array}{l}\text { - Filosofia e tecnologia } \\
\text { do ensino moderno }\end{array}$} & \multirow{3}{*}{$\begin{array}{lcr}\text { A } & \text { aula } & \text { como } \\
\text { proporcionador } & \text { de } \\
& \text { atividades }\end{array}$} \\
\hline & $\begin{array}{l}\text { A psicologia do pensamento } \\
\text { e a natureza psicológica } \\
\text { das operações lógicas }\end{array}$ & & \\
\hline & \begin{tabular}{|ccc}
$A$ & inteligência e \\
percepção.
\end{tabular} & \multirow{2}{*}{$\begin{array}{l}\text { Noção curricular } \\
\text { moderna }\end{array}$} & \\
\hline & $\begin{array}{c}\text { O hábito e a inteligência } \\
\text { senso-motora }\end{array}$ & & \multirow{4}{*}{$\begin{array}{l}\text { Situações de } \\
\text { aprendizagem e etapas } \\
\text { do ensino produtivo }\end{array}$} \\
\hline & $\begin{array}{l}\text { A elaboração } \\
\text { pensamento- intuição e } \\
\text { operações }\end{array}$ & $\begin{array}{c}\mathrm{O} b \text { i e } t \mathrm{i} v \text { o } \\
\text { comportamentais } \\
\text { como resultados de } \\
\text { aprendizagem }\end{array}$ & \\
\hline & $\begin{array}{lr}\text { Fatores } & \text { sociaisde } \\
\text { desenvolvimento intelectual. }\end{array}$ & \multirow{2}{*}{$\begin{array}{l}\text { Projeção do ensino } \\
\text { moderno }\end{array}$} & \\
\hline & $\begin{array}{l}\text { Didática fundamentada na } \\
\text { teoria de Piaget Psicológica. }\end{array}$ & & \\
\hline
\end{tabular}


Quadro I - Síntese dos conteúdos listados nos planos de ensino de Didática (continuação)

\begin{tabular}{|c|c|c|c|}
\hline & 1981 & 1982 & 1985 \\
\hline & $\begin{array}{c}\text { O impacto da tecnologia na } \\
\text { educação }\end{array}$ & $\begin{array}{lr}\text { Diagnóstico } & \text { da } \\
\text { realidade: } & \text { menor } \\
\text { carente } & \end{array}$ & \begin{tabular}{|lrr} 
A educação & e & suas \\
relações & com & as \\
dimensões & históricas, \\
sociais, & filosóficas, \\
psicológicas & e \\
\multicolumn{2}{c}{ metodológicas }
\end{tabular} \\
\hline & $\begin{array}{l}\text { A inteligência e a percepção } \\
\begin{array}{l}\text { O preparo do educador: as } \\
\text { novas tarefas do professor. }\end{array}\end{array}$ & $\begin{array}{lr}O & \text { impacto } \quad d a \\
\text { tecnologia na educação }\end{array}$ & $\begin{array}{cc}\text { A } & \text { formação do } \\
\text { professor }\end{array}$ \\
\hline @ & $\begin{array}{c}\text { A persistência de padrões } \\
\text { anacrônicos na educação } \\
\text { dos trabalhos de classe }\end{array}$ & \begin{tabular}{|c|}
$\begin{array}{c}\text { A criatividade e a } \\
\text { consciência crítica no } \\
\text { processo educacional }\end{array}$ \\
$\begin{array}{c}\text { Novas tarefas do } \\
\text { professor }\end{array}$
\end{tabular} & $\begin{array}{c}\text { A Didática e sua } \\
\text { implicação no } \\
\text { pedagógico }\end{array}$ \\
\hline 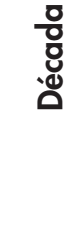 & $\begin{array}{l}\text { contexto social e a } \\
\text { realidade educacional }\end{array}$ & \begin{tabular}{|c|}
$\begin{array}{c}\text { processo de } \\
\text { atendimento individual. }\end{array}$ \\
$\begin{array}{c}\text { Técnicas inovadoras de } \\
\text { ensino }\end{array}$
\end{tabular} & $\begin{array}{l}\text { Concepção } \\
\text { currículo escolar }\end{array}$ \\
\hline & $\begin{array}{c}\text { Técnicas inovadoras de } \\
\text { ensino }\end{array}$ & $\begin{array}{l}\text { A pesquisa e a } \\
\text { implementação } \\
\text { currículos nas escolas }\end{array}$ & $\begin{array}{l}\text { Os componentes do } \\
\text { plano curricular }\end{array}$ \\
\hline & $\begin{array}{l}\text { Os princípios da ação } \\
\text { Didática no desenvolvimento } \\
\text { da linguagem }\end{array}$ & A avaliação do ensino. & $\begin{array}{l}\text { planejamento } \\
\text { didático }\end{array}$ \\
\hline
\end{tabular}


Quadro I - Síntese dos conteúdos listados nos planos de ensino de Didática (continuação)

\begin{tabular}{|c|c|c|c|}
\hline \multirow{11}{*}{ 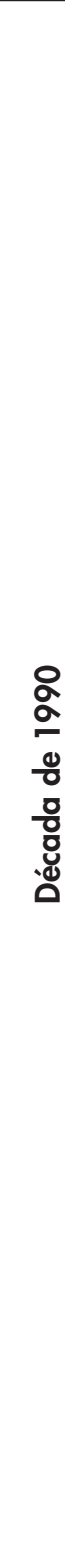 } & 1994 & 1996 & 1997 \\
\hline & $\begin{array}{r}\text { Profissionalização } \\
\text { professor }\end{array}$ & \begin{tabular}{|c|}
$\begin{array}{c}\text { Retrospectiva histórica } \\
\text { da Didática }\end{array}$ \\
$\begin{array}{c}\text { A Didática e a formação } \\
\text { de educadores }\end{array}$ \\
\end{tabular} & \multirow{2}{*}{$\begin{array}{l}\text { Comênio, } \\
\text { Dewey e Herbat, } \\
\text { Freire: um paulo } \\
\text { do desenvolvimento } \\
\text { histórico da Didática }\end{array}$} \\
\hline & \multirow{2}{*}{$\begin{array}{c}\text { Fundamentos teóricos do } \\
\text { ensino }\end{array}$} & $\begin{array}{l}\text { Tendências pedagógicas } \\
\text { e a ação docente }\end{array}$ & \\
\hline & & $\begin{array}{l}\text { O processo de ensino na } \\
\text { escola }\end{array}$ & \multirow[b]{2}{*}{$\begin{array}{l}\text { A Didática e a } \\
\text { formação profissional } \\
\text { do educador }\end{array}$} \\
\hline & \multirow{4}{*}{$\begin{array}{c}\text { Planejamento da ação } \\
\text { Didática. }\end{array}$} & \begin{tabular}{|l|} 
Os componentes didáticos \\
e seu desenvolvimento \\
nas situações de ensino \\
aprendizagem: objetivos, \\
conteúdos, métodos, \\
\multicolumn{2}{c}{ recurso e avaliação } \\
\end{tabular} & \\
\hline & & $\begin{array}{l}\text { A aula como forma de } \\
\text { organização do ensino. }\end{array}$ & \multirow{2}{*}{$\begin{array}{l}\text { T e n d ê n c i a s } \\
\text { pedagógicas e a ação } \\
\text { docente }\end{array}$} \\
\hline & & $\begin{array}{c}\text { A relação professor- } \\
\text { aluno }\end{array}$ & \\
\hline & & \begin{tabular}{|ccc} 
O planejamento do \\
ensino e o plano de \\
aulas
\end{tabular} & \multirow{2}{*}{$\begin{array}{l}\text { Diferentes aspectos } \\
\text { do ensino: objetivos, } \\
\text { conteúdo, método e } \\
\text { avaliação }\end{array}$} \\
\hline & \multirow{3}{*}{$\begin{array}{l}\text { O professor e a qualidade } \\
\text { do ensino }\end{array}$} & \begin{tabular}{|c|c|}
$O$ professor e & a \\
qualidade do ensino
\end{tabular} & \\
\hline & & $\begin{array}{c}\text { Profissionalização do } \\
\text { professor }\end{array}$ & \multirow{2}{*}{$\begin{array}{l}\text { A organização do } \\
\text { trabalho pedagógico } \\
\text { frente as novas } \\
\text { tecnologias }\end{array}$} \\
\hline & & A interdisciplinariedade & \\
\hline
\end{tabular}


Quadro I - Síntese dos conteúdos listados nos planos de ensino de Didática (continuação)

\begin{tabular}{|c|c|c|c|}
\hline \multirow{11}{*}{ 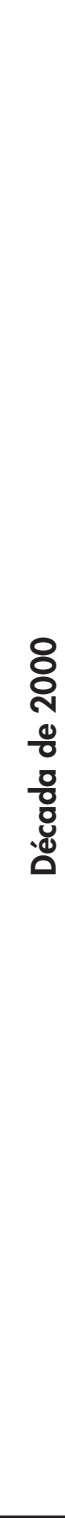 } & 2008 & 2011 & 2018 \\
\hline & $\begin{array}{l}\text { O professor, identidade, } \\
\text { especificidade }\end{array}$ & $\begin{array}{l}\text { Oranhecimento } \\
\text { didático e suas relações } \\
\text { com as demais áreas do } \\
\text { conhecimento }\end{array}$ & $\begin{array}{l}\text { Especificidade da } \\
\text { Didática como área de } \\
\text { conhecimento }\end{array}$ \\
\hline & & \multirow{3}{*}{$\begin{array}{l}\text { A ação Didática e a sua } \\
\text { inserção na cultura }\end{array}$} & $\begin{array}{c}\text { Papéis e funções do } \\
\text { professor }\end{array}$ \\
\hline & \multirow{2}{*}{$\begin{array}{l}\text { A relação pedagógica } \\
\text { professor, } \\
\text { conhecimento aluno, } \\
\text { diferentes aspectos de } \\
\text { ensinar e aprender }\end{array}$} & & $\begin{array}{l}\text { Formação de } \\
\text { professores e ensino, } \\
\text { pesquisa e extensão }\end{array}$ \\
\hline & & & \multirow{2}{*}{$\begin{array}{c}\text { Categorias didáticas: } \\
\text { objetivos/avaliação, } \\
\text { conteúdos/métodos, } \\
\text { tempos/espaços e o } \\
\text { planejamento da ação } \\
\text { didática }\end{array}$} \\
\hline & \multirow{4}{*}{$\begin{array}{l}\text { Planejamento } \\
\text { organização do ensino: } \\
\text { objetivo, avaliação, } \\
\text { conteúdos, métodos na } \\
\text { escola e em outros espaços } \\
\text { pedagógicos }\end{array}$} & $\begin{array}{llr}\text { A educação, os } & \text { de } \\
\text { processos } & & \text { de } \\
\text { escolarização e } & \text { a }\end{array}$ & \\
\hline & & $\begin{array}{l}\text { formalização da ação } \\
\text { Didática, a partir dos } \\
\text { significados históricos } \\
\text { culturais locais e globais }\end{array}$ & \multirow[t]{2}{*}{$\begin{array}{l}\text { Diferentes aspectos do } \\
\text { ensinar e do aprender }\end{array}$} \\
\hline & & \multirow{2}{*}{$\begin{array}{l}\text { A relação pedagógica } \\
\text { professor, aluno, } \\
\text { conhecimento e os } \\
\text { diferentes aspectos de } \\
\text { ensinar e aprender }\end{array}$} & \\
\hline & & & \begin{tabular}{|lr} 
Dewey, & Maria \\
Montessori, & Jean \\
Piaget, Paulo & Freire,
\end{tabular} \\
\hline & \multirow{2}{*}{$\begin{array}{l}\text { Didática e comunicação: } \\
\text { a sala de aula como } \\
\text { espaço comunicativo, as } \\
\text { tecnologias da informação } \\
\text { e os recursos didáticos }\end{array}$} & $\begin{array}{l}\text { Os sujeitos, as novas } \\
\text { subjetividades e os novos } \\
\text { objetos da educação nos } \\
\text { cruzamentos culturais }\end{array}$ & $\begin{array}{l}\text { da Costa, Fernando } \\
\text { Francisco de Gois, } \\
\text { Maria Cândida de } \\
\text { Moraes, Edgar Morin } \\
\end{array}$ \\
\hline & & $\begin{array}{l}\text { A formação docente e } \\
\text { suas especificidades no } \\
\text { mundo contemporâneo }\end{array}$ & $\begin{array}{c}\text { Mapas } \underset{\text { enceituais }}{\text { e redes }} \\
\text { cons }\end{array}$ \\
\hline
\end{tabular}

Fonte: Elaborada pelos autores (2019).

Após a análise dos planos de ensino, a partir de sua desmontagem e fragmentação e, em seguida, o processo de unitarização, buscou-se a 
Ensino da Didática no curso de licenciatura em pedagogia

identificação das unidades de significado, definindo as categorias, formadas a partir da análise das ementas e conteúdos indicados nos planos de ensino. Das análises, sobressaem as categorias de abordagem da Didática: (i) Didática com abordagem em psicologia, (ii) Didática com abordagem no tecnicismo, (iii) Didática com abordagem sociopolítica, (iiii) Didática com abordagem no ensino e na profissionalização do professor.

\section{(i) Didática com ênfase na psicologia}

Ao verificarmos a expressão dos conteúdos ao longo do curso de Pedagogia, identificamos que, no início da década de 1970, a proposta do ensino de Didática adota uma abordagem de ênfase Psicológica, valorizando a aprendizagem com base nas teorias piagetianas. Estão listados como conteúdos: inteligência e adaptação biológica. A psicologia do pensamento e a natureza psicológica das operações lógicas; a inteligência e a percepção; a inteligência e a percepção; o hábito e a inteligência senso-motora; a elaboração do pensamento - intuição e operações; fatores sociais de desenvolvimento intelectual; didática fundamentada na teoria psicológica de Piaget.

Neste sentido, o estudo de Tezza (2018, p. 32-33) aponta que, neste periódico na FFCUnesp/Marília, a Didática segue com "[...] fundamentação em teorias psicológicas para o estudo da aprendizagem [...]" bem como, "[... ] preocupação em trabalhar o ensino individualizado e a criação de métodos com o intuito de se obter uma participação mais ativa dos alunos". Reis (2017), ao examinar as revistas de Educação do período de 1945 a 1961 , encontra artigos com embasamento em John Dewey e Maria Montessori que focalizaram a Didática. Na Didática desenvolvida nos cursos de Pedagogia na UFPR nos anos de 1969 a 1972, o ensino era desenvolvido em laboratórios, considerando a Didática Geral e as Didáticas Específicas, denominadas de metodologia de ensino de Língua Portuguesa, Metodologia de Ensino de Matemática, Metodologia de Ensino de Biologia e Metodologia de Ensino de Artes.

Os laboratórios eram constituídos de salas ambientes de acordo com a metodologia a que se destinavam. Por exemplo, para Metodologia de Ensino de Matemática os jogos de blocos lógicos, material dourado, formas, volume, peso, enfim, materiais para sistema de numeração decimal, trabalho com 
conjunto, figuras geométricas, medidas. $\bigcirc$ laboratório de Didática possuía móveis construídos numa perspectiva montessoriana formando uma oval, para rodas de conversa e discussões. Os estudos realizados envolviam fundamentos de aprendizagem por meio de textos, realização de atividades investigativas e realização de atividades centradas na aprendizagem. As aulas não eram expositivas, contavam com a participação dos estudantes. $\bigcirc$ registro da aprendizagem era feito em forma de diários denominados dossiês, contendo textos, reflexões, anotações e observações.

Os estudos fundamentados em Piaget, Montessori, Gagné, Dienes, formavam os textos examinados, em que os estudantes elaboravam seus roteiros de estudos e comentários, portanto, de abordagem escolanovista com base psicológica. Como alerta Veiga (1994), o ensino da Didática neste período respeitava as individualidades e o professor se tornava o facilitador da aprendizagem, num caráter prático-técnico, em que teoria e prática eram justapostas, valorizando a dimensão instrumental.

\section{(ii) Didática com ênfase no tecnicismo}

Como destacado anteriormente no decorrer da década de 1970 o ensino da Didática passou a ter como abordagem uma Didática tecnicista, iniciada com uma perspectiva racionalista. $\bigcirc$ ensino da Didática no curso de Pedagogia, na UFPR, indica como conteúdos no programa de 1975: Filosofia e tecnologia do ensino moderno, noção curricular moderna, objetivos comportamentais como resultados de aprendizagem, projeção do ensino moderno. Nessa abordagem, segundo Martins (2012, p. 92) "[...] situações de aprendizagem e etapas do ensino produtivo [...]", aos estudantes era necessário "[...] dar respostas específicas definidas nos objetivos operacionais [...]", por um professor tecnicamente competente.

A aula como proporcionador de atividades e situações de aprendizagem e etapas do ensino produtivo fazia parte dos conteúdos no programa de 1978. Ao indicar a tecnologia do ensino moderno e os objetivos comportamentais, expressa uma abordagem tecnicista. A inclusão da relação com o currículo pode estar relacionada ao recém-criado Programa de Pós-Graduação em Educação, cuja linha de concentração era currículo, pois muitos professores 
Ensino da Didática no curso de licenciatura em pedagogia

de Didática deste período realizavam sua qualificação em mestrado neste programa.

A disciplina de Didática na proposta de reformulação do curso de pedagogia de 1981 teve denominação de Introdução aos Métodos Pedagógicos e Didáticos e integrou as disciplinas do Núcleo Comum (PEDRA, 1982). $\bigcirc$ conteúdo do programa mantém manteve as disciplinas: $\bigcirc$ Impacto da Tecnologia na Educação; Técnicas Inovadoras de Ensino; A Avaliação do Ensino em Função dos Objetivos; Perspectiva para a Inovação e Inclusão. No entanto, nesse ano estavam indicadas duas outras vertentes: o preparo do educador, as novas tarefas do professor e $\bigcirc$ contexto social e a realidade educacional. Desse modo, se inicia uma fase de transição entre a abordagem tecnicista para a abordagem de formação centrada no educador como expressa a proposta do curso (PEDRA, 1982).

Em 1982, a ementa foi alterada, restringindo alguns itens do ano anterior tais como - estratégia educacional e a motivação docente; os princípios da ação Didática no desenvolvimento da linguagem, e reduziu a ênfase na abordagem tecnicista, ampliando para uma abordagem centrada na formação do educador incluindo assuntos como segue: novas tarefas do professor e 18 o processo de atendimento individual.

\section{(iii) Didática com abordagem sociopolítica}

A década de 1980 foi marcada pela reabertura política do país com denúncias de uma educação assentada na transmissão e assimilação e questiona-se: educação para quê? A favor de quem? É neste cenário que a formação de professores passa a realizar uma revisão crítica, a partir da compreensão que a educação é uma prática social. No tocante a essas discussões o curso de Pedagogia passa a conceber o ensino de Didática com ênfase sociopolítica.

A ênfase sociopolítica no ensino de Didática, materializou-se no mesmo período em que ocorreu o segundo encontro da "Didática em questão" (MARTINS, 1998). Ocorreu a ampliação acerca das especificidades da formação de professores para a educação básica e um movimento de denúncia contra o ensino assentado em práticas descoladas das relações sociais estabelecidas no interior da sociedade. Candau (1984, p. 19) ressalta que 
neste momento começou-se a despertar para a "[...] importância da dimensão política até então silenciada pela perspectiva instrumental, fundada na neutralidade da técnica". Os conteúdos expressos no plano de ensino da disciplina de Didática "[...] o contexto social e a realidade educacional, diagnóstico da realidade: menor carente, a criatividade e a consciência crítica no processo educacional [...]" (UFPR, 1982) reportaram as alterações indicadas nas discussões do encontro de Didática, num movimento que emergiu no interior da formação do curso de licenciatura em Pedagogia para responder a essas questões, numa perspectiva que considera as dimensões humana, técnica e política social, aliadas à prática pedagógica concreta (MARTINS, 1998). Ao longo da década de 1980, a disciplina de Didática passou por um momento de reconstrução, tomando como base a relação teoria/prática, a produção do conhecimento e o comprometimento com a transformação social.

Nesse cenário e como consequência desse movimento de reestruturação da Didática, passa-se a destacar o currículo nessa relação, a Didática manteve sua ênfase sociopolítica e, junto a ela, inferiu o estudo do currículo. No Paraná, a década de 1980/1990 representou um marco, uma vez que o estado realizava a construção do seu currículo para a educação básica e, para isso, definiu como concepção de educação a pedagogia histórico-crítica, que compreende a educação como mediação no seio da prática social global (SAVIANI, 2008), ou seja, assentada na concepção de mundo e de homem a partir do materialismo histórico.

A proposta de 1985 de Didática no curso de pedagogia apontou para essa abordagem sócio-histórica ao indicar como itens de conteúdo: a educação e suas relações com as dimensões históricas, sociais, filosóficas, psicológicas e metodológicas e a Didática e sua implicação no ato pedagógico. Considerando o movimento de reformulação curricular neste período, verifica-se a inclusão de itens nesta perspectiva na proposta daquele ano de 1985: concepção de currículo escolar, os componentes do plano curricular e o planejamento didático. 


\section{(iiii) Didática com abordagem no ensino e na profissionalização do professor}

Frente às alterações no ensino da Didática, a década de 1990, passou a ter como ênfase a profissionalização do professor, reconhecendo a relação com o processo de formação docente. Nessa perspectiva, a concepção da formação de professores destaca a profissionalização do professor, que se caracteriza por "[...] um processo permanente de construção e não se restringe a aquisição, é uma conduta" (ROMANOWSKI, 2010, p. 37). Essa perspectiva valoriza a relação pedagógica da docência e compreende que sua função política reside na relação entre os professores, as determinações das políticas governamentais e a comunidade escolar (ROMANOWSKI, 2010|. Essas relações estão imbricadas nos saberes docentes, que se constituem ao longo do processo de escolarização dos cursos de formação e na prática profissional.

A Didática, nesta perspectiva de abordagem na profissionalização do professor, está expressa na listagem de conteúdos de 1994: profissionalização do professor; fundamentos teóricos do ensino; planejamento da ação

20 Didática; o professor e a qualidade do ensino. A indicação desses conteúdos relativos à formação e profissionalização do professor estão presentes nos anos de 1996 a 2018 , em todos os programas. No entanto, a partir do programa de 1996 foram propostas: tendências pedagógicas e a ação docente; o processo de ensino na escola; os componentes didáticos e seu desenvolvimento nas situações de ensino aprendizagem: objetivos, conteúdos, métodos, recursos e avaliação. A isso se acresce: a relação pedagógica professor, aluno, conhecimento e os diferentes aspectos de ensinar e aprender, ou seja, não só os elementos da composição do ensino, mas os sujeitos professor e alunos. Ainda, como conteúdo comum em todos os programas a partir de 2008: o conhecimento didático e suas relações com as demais áreas do conhecimento.

Nas listagens de 2008 a 2018 aparecem conteúdos que não se repetem nos demais anos: a ação Didática e a sua inserção na cultura; os sujeitos, as novas subjetividades e os novos objetos da educação nos cruzamentos culturais; mapas e redes conceituais. No programa de 2008: didática e comunicação: a sala de aula como espaço comunicativo, as tecnologias da informação e os recursos didáticos. E, em 1997 e 2018, alguns teóricos da Didática e em alguns programas a aula como item do conteúdo. Desse modo, 
o ensino e a formação e profissionalização do professor se constituem itens de conteúdos presentes em todos os programas nestas três décadas, portanto, uma Didática com abordagem no ensino e na profissionalização do professor. No entanto, destacamos que o trabalho com a construção histórica do processo de ensino compreende autores clássicos e novos autores que problematizam a organização do trabalho pedagógico do professor como Herbart, Dewey, Maria Montessori, Jean Piaget, Paulo Freire, Antonio Carlos Gomes da Costa, Fernando Francisco de Gois, Maria Cândida de Moraes, Edgar Morin" (UFPR, 2018).

A escola passa a ser valorizada enquanto lócus da construção de saberes e de conhecimentos e a universidade como local de produção desse conhecimento que não é descolado das práticas realizadas no interior das escolas, que expressam determinada educação do homem para a vida em sociedade (VEIGA, 1994). Compreendemos, nessa perspectiva, a valorização do ensino da Didática como transformação da prática pedagógica da escola, por meio da concepção de homem, de mundo, determinada por diferentes relações sociais ao buscar a formação e a profissionalização do professor.

estudo aponta as mediações entre as determinações sociais e culturais, ao longo do período de 1970 a 2018, do ensino de Didática e o contexto da sociedade em que se efetiva. Nos anos de 1960 a 1978 as marcas do psicologismo na racionalidade técnica (ROSA, 1989; MARTINS, 1989; VEIGA, 1994; CANDAU, 1984), transformadas nos anos de 1982 a 1985 em propostas sensíveis ao reconhecimento das necessidades educacionais dos alunos no contexto em que se situam. Nos anos de 1994 a 1997, as propostas reconheceram a relação entre Didática e formação de professores, defenderam os fundamentos da disciplina e reconheceram a integração das tecnologias no ensino. Nos anos 2008 a 2018 essa abordagem foi mantida e a ela se acresceu a dimensão da aprendizagem.

\section{Considerações finais}

Consideramos que a investigação desenvolvida permitiu compreender a Didática como uma área de formação do professor que vem sofrendo alterações ao longo da história pelas implicações da política educacional, das 
Ensino da Didática no curso de licenciatura em pedagogia

pesquisas acadêmicas, das discussões no campo disciplinar da Didática, da Pedagogia e da organização da escola, em especial a prática docente.

A Didática, ao considerar o processo de ensino e aprendizagem, isto é, o professor, os alunos e o conhecimento na dinâmica da prática pedagógica, se constitui conhecimento fundante para a docência que se concretiza no espaço e tempo escolar, portanto, conhecimento poderoso para formação e a profissionalização docente.

Neste estudo, que examinou os programas de Didática do curso de pedagogia da UFPR desde a década de 1970 até 2018, identificamos a relação entre a Didática e a conjuntura das políticas educacionais, a sociedade e a universidade. As abordagens do ensino de Didática desse curso se situam no contexto das tendências do ensino da Didática. Foi possível verificar que o ensino na disciplina de Didática na UFPR acompanhou as legislações vigentes e suas alterações, mas, sobretudo, num processo em que materializou as tendências educacionais em sua prática, presentes nas marcas dos conteúdos formadores que expressam formas de resistência em torno de determinações políticas. Às vezes, essa resistência se expressa em apenas um item de conteúdo, contudo, é presente.

Um estudo, mais aprofundado sobre as referências dos programas, sobre os professores que ministraram esta disciplina, poderá ampliar e aprofundar os resultados desta investigação, permitindo afirmativas em torno de uma proposta que guarda o universal e o local, portanto, uma identidade própria do programa de Didática desse curso nessa instituição.

No estudo dos conteúdos explicitados nessa pesquisa, identificamos que a disciplina de Didática sempre esteve presente no curso de licenciatura em Pedagogia e que materializa o caráter político na Educação, ultrapassando as práticas instrumentais e descoladas da sociedade como um todo, principalmente, a partir da década de 1980. A formação com ênfase na Didática sociopolítica está presente na disciplina de Didática desde a década de 1980 até os dias atuais. Essa disciplina compreende, na atualidade, a unidade entre aprender e ensinar, articulada a dimensão epistemológica, psicopedagógica e sociocultural.

Ao longo deste período dos anos de 1972 a 2018, os programas do ensino de Didática no curso de Pedagogia são perpassados por um tecnicismo, que busca uma nova abordagem sócio-histórica comprometida com 
a formação e profissionalização do professor pela compreensão do processo ensino aprendizagem. Essas mudanças, nem sempre perceptíveis nas práticas escolares em que os pedagogos oriundos deste curso atuam, ensejam questões e reflexões permanentes, sobre as determinações nos cernes dos programas. É possível afirmar que os programas expressam mudanças atreladas às pesquisas que analisam o ensino de Didática como propõe André (1985) e Cruz (2017), mas, ao mesmo tempo, são mediadas pelos determinantes socio políticos expresso em Rosa (1989), Martins (1998), Freitas (2016). Oxalá o ensino de Didática resista às novas ondas conservadoras e neoliberais que se anunciam nestes novos tempos.

\section{Notas}

1 USAID - United States Agency for International Development. Agência norte-americana com a qual o Ministério da Educação e Cultura celebrou acordos para a reordenação da educação nacional (VEIGA, 2004).

2 Em 2020 acontecerá o XX Encontro Nacional de Didática e Prática de Ensino, no Rio de Janeiro, com a proposição de tema: Fazeres-saberes pedagógicos: diálogos, insurgências e políticas.

3 termo abordagem é fundamentado em Mizukami (1986).

4 Anotações de Joana Paulin Romanowski, estudante do curso de Pedagogia no período de 1969 a 1972.

5 materialismo histórico diz respeito à totalidade dos processos de criação e recriação da realidade humano-social mediados pelo trabalho, pelos quais o ser humano confere humanidade às coisas da natureza e humaniza-se com as criações e representações que produz sobre o mundo (SAVIANI, 2009).

\section{Referências}

ANDRÉ, Marli Eliza Dalmazo Afonso de. Em busca de uma didática fundamental. Trabalho apresentado no Seminário "A Didática em Questão", São Paulo, 1985.

AZEVEDO, Fernando de. A reconstrução educacional do Brasil: ao povo e ao governo. Manifesto dos Pioneiros da Educação Nova. Rio de Janeiro: 1932. Disponível em: http:// www.dominiopublico.gov.br/download/texto/me4707.pdf. Acesso em: 20 dez. 2018.

BARDIN, Laurence. Análise de conteúdo. São Paulo: Edições 70, 2011.

BRASIL. Decreto-Lei $\mathbf{n}^{\circ} \mathbf{1} 190$, de 4 de abril de 1939. Dá organização à Faculdade Nacional de Filosofia. Disponível em: http://www2.camara.leg.br/legin/fed/

declei/1930-1939/decreto-lei-1 190-4-abril-1939-34924 1-publicacaooriginal-1-pe.html. Acesso em: 22 dez. 2018. 
Ensino da Didática no curso de licenciatura em pedagogia

BRASIL. Lei $\mathbf{n}^{\circ}$ 4.024, de 20 de dezembro de 1961. Lei de Diretrizes e Bases da Educação Nacional. Fixa as Diretrizes e Bases da Educação Nacional. Disponível em: http: / /wwwp. fc.unesp.br/ lizanata/LDB\%204024-61.pdf. Acesso em: 18 dez. 2018.

BRASIL. Lei $\mathbf{n}^{\circ}$ 5692, de 11 de agosto de 1971. Fixa Diretrizes e Bases para o Ensino de $1^{\circ}$ e $2^{\circ}$ graus. Disponível em: http://www.planalto.gov.br/ccivil_03/leis/I5692.htm>. Acesso em: 8 maio 2019.

BRASIL. Lei $\mathbf{n}^{\circ} \mathbf{7 . 0 4 4}$, de 18 de outubro de 1982. Altera dispositivos da Lei $n^{\circ}$ 5.692, de 11 de agosto de 1971, referentes à profissionalização do ensino de $2^{\circ}$ grau. Disponível em: http://www.planalto.gov.br/ccivil_03/leis/L7044.htm. Acesso em: 18 dez. 2018.

BRASIL. Constituição da República Federativa do Brasil. Disponível em: http:/ / www.planalto.gov.br/ccivil_03/constituicao/ConstituicaoCompilado.

htm. Acesso em: 18 dez. 2018.

BRASIL. Lei $\mathbf{n}^{\circ}$ 9.394, de 20 de dezembro de 1996. Estabelece as Diretrizes e Bases da Educação $N$ acional. Diário Oficial da União, Brasília, DF, 23 dez. 1996. Disponível em: http://www. planalto.gov.br/ccivil_03/LEIS/L9394.htm. Acesso em: 19 dez. 2018.

BRASIL. Conselho Federal de Educação - CFE. Parecer n²51/1962. Currículo mínimo e duração do Curso de Pedagogia. Relator: Valnir Chagas. Documenta, Brasília, n. 1 1, p. 24 59-65, 1963.

BRASIL. Resolução CNE/CP n 1, de 18 de fevereiro de 2002. Institui Diretrizes Curriculares Nacionais para a Formação de Professores da Educação Básica, em nível superior, curso de licenciatura, de graduação plena. Disponível em: http://portal.mec.gov.br/cne/arquivos/pdf/rcp01_02.pdf Acesso em: 18 maio 2019.

BRASIL. Resolução n 1, de maio de 2006: Diretrizes Curriculares Nacionais para o Curso de Pedagogia. Disponível em: http://portal.mec.gov.br/cne/arquivos/pdf/rcp01_06. pdf. Acesso em: 19 dez. 2018

BRASIL. Resolução CNE/CP nº 02/2015, de $1^{\circ}$ de julho de 2015. Diretrizes Curriculares Nacionais para a Formação Inicial em Nível Superior (cursos de licenciatura, cursos de formação pedagógica para graduados e cursos de segunda licenciatura) e para a formação continuada. Brasília, DF, Diário Oficial [da] República Federativa do Brasil, n. 124, p. 8-12, seção 1, 2015. Disponível em: http://portal.mec.gov.br/docman/agosto-2017pdf/70431-res-cne-cp-002-03072015-pdf/file. Acesso em: 21 jun. 2019.

BRASIL. Resolução CNE/CP N 1, de 15 de maio de 2006. Institui Diretrizes Curriculares Nacionais para o Curso de Graduação em Pedagogia, licenciatura. Conselho Nacional de Educação. Disponível em: http://portal.mec.gov.br/cne/arquivos/pdf/rcp0 1_06.pdf. Acesso em: 20 mar. 2019. 
CANDAU, Vera Maria Ferrão. A didática em questão. Petrópolis: Vozes, 1984.

CRUZ, Giseli Barreto da. Didática e docência no ensino superior. Revista Brasileira de Estudos Pedagógicos, Brasília, v. 98, n. 250, p. 672-689, dez. 2017. Disponível em: http:// www.scielo.br/scielo.php? script=sci_arttext\&pid=\$2 176-66812017000300672\&lng=pt \&nrm=iso. Acesso em: 29 ago. 2019.

CRUZ, Giseli Barreto da; ANDRÉ, Marli. $\bigcirc$ ensino de didática e o aprendizado da docência na visão de professores formadores. Diálogo Educacional, Curitiba, v. 12, n. 35, p. 79-101, jan./abr. 2012.

FREITAS, Helena Costa Lopes de. Formação de professores no Brasil: 10 anos de embate entre projetos de formação. Educação \& Sociedade, Campinas, v. 23, n. 80, p. 136-167, set. 2002. Disponível em: http://www.scielo.br/pdf/es/v23n80/12928.pdf. Acesso em: 9 maio. 2016.

GATTI, Bernadete Angelina. Professores do Brasil: impasses e desafios. Brasília: UNESCO, 2009.

GATTI, Bernardete Angelina. Formação de professores no brasil: características e problemas. Educação \& Sociedade, Campinas, v. 31, n. 113, p. 1355-1379, out./dez. 2010. Disponivel em: https://www.redalyc.org/pdf/873/87315816016.pdf. Acesso em: 20 mar. 2019.

GONCCALVES, Nadia Gaiofatto. VIEIRA, Carlos Eduardo. Formação de Professores no Setor de educação da Universidade Federal do Paraná (1938-2010). Educação \& Realidade, Porto Alegre, v. 41 , p. 1441-1464, dez. 2016. (número especial). Disponível em: http:// dx.doi.org/10.1590/2175-623667656. Acesso em: 22 mar. 2019.

INEP. Instituto Nacional de Estudos e Pesquisas Educacionais Anísio Teixeixa. Sinopse Estatística da Educação Básica. 2018. Disponível em: http://inep.gov.br/web/guest/ sinopses-estatisticas-da-educacao-basica. Acesso em: 20 mar. 2019.

LÜDKE, Menga; ANDRÉ, Marli Eliza Dalmazo Afonso de. Pesquisa em educação: abordagens qualitativas. 2 ed. São Paulo: EPU, 2013.

MACHADO, Suelen Fernanda; TERUYA, Teresa Kazuko. O Manifesto de 1932 e as repercussões na formação de professores da rede pública de ensino. Disponível em: <http:// www.histedbr.fe.unicamp.br/acer_histedbr/jornada/jornada7/_GT2\%2OPDF/O\%20 MANIFE 129. Acesso em: 19 mar. 2019.

MARCELO, Carlos Garcia. Formação de professores: para uma mudança educativa. Porto: Porto Editora, 1999. 
Ensino da Didática no curso de licenciatura em pedagogia

MARTINS, Lígia Márcia; DUARTE, Newton (Org.) Formação de professores: limites contemporâneos e alternativas necessárias. São Paulo: UNESP, Cultura Acadêmica, 2010. Disponível em: http://books.scielo.org/id/ysnm8/pdf/martins-9788579831034.pdf. Acesso em: 18 mar 2019.

MARTINS, Pura Lúcia Oliver; ROMANOWSKI, Joana Paulin. A didática na Formação Pedagógica de Professores. Educação, Porto Alegre, v. 33, p. 205- 212, set./dez., 2010. MIZUKAMI, Maria da Graça Nicoletti. Ensino: as abordagens do processo. São. Paulo: EPU, 1986.

MARTINS, Pura Lúcia Oliver. A didática e as contradições da prática. Campinas: Papirus, 1998.

MARTINS, Pura Lúcia Oliver. A didática e as contradições da prática. 3. ed. Campinas: Papirus, 2009.

MARTINS, Pura Lúcia Oliver. Didática. Curitiba: Intersaberes, 2012.

PEDRA, José Alberto (Coord.). Nova proposta curricular para o curso de pedagogia da Universidade Federal do Paraná. Educar em Revista, Curitiba, n. 2, p. 163-180, dez. 1982. Disponível em: http://www.scielo.br/scielo.php? script=sci_arttext\&pid=S0 104$-40601982000100010 \&$ lng=en\&nrm=iso. Acesso em: 12 jun. 2019.

26 PEREIRA, Júlio Emílio Diniz. As licenciaturas e as novas políticas educacionais para a formação docente. Educação \& Sociedade, Campinas, v. 20, n. 68, p. 109-125, dez. 1999. Disponível em: http://www.scielo.br/pdf/es/v20n68/a06v2068.pdf. Acesso em: 13 mar. 2019.

REIS, Karina Cassia Oliveira Reis. As revistas educação (1931-1932), revista de educação (1933-1944) e revista de educação (1945-1961) como fóruns de discussões sobre didática. Dissertação (Mestrado em Educação) - Universidade Estadual Paulista "Júlio de Mesquita Filho" (Marilia), 2017. Disponível em: reis_kco_me_mar.pdf. Acesso em: 19 ago. 2019.

ROMANOWSKI, Joana Paulin. Formação e profissionalização docente. 3. ed. Curitiba: IBPEX, 2010.

ROMANOWSKI, Joana Paulin; MARTINS, Pura Lúcia Oliver; CARTAXO, Simone Manosso (Org.). Práticas de formação de professores: da educação básica ao ensino superior. Curitiba: PUCexpress, 2016.

ROSA, Celina Maria Bezerra Santa. A didática e a tecnologia educacional: coerência e pertinência. Revista Educação em Questão, Natal, v. 3, n. 2, p. 30-38, jul./dez, 1989. Disponível em: https://periodicos.ufrn.br/educacaoemquestao/article/view/ 11362. Acesso em: 12 nov. 2019. 
SAVIANI, Dermeval. Pedagogia histórico-crítica: primeiras aproximações. 10 ed. Campinas: Autores Associados, 2008.

SAVIANI, Dermeval. Escola e democracia: teorias da educação, curvatura da vara, onze teses sobre a educação política. Campinas: Autores Associados, 2009.

SAUTHIER, Kelen Doopiati; JUNGES, Kelen dos Santos. Pressupostos teóricos e percepções docentes em torno da didática. Revista Ensino \& Pesquisa, Paranavaí, v. 14, n. 1, 2016 , p. 12-24. Disponível em: http://periodicos.unespar.edu.br/index.php/ensinoepesquisa/ article/view/405/523. Acesso em: 20 mar. 2019.

SCHEIBE, Leda; BAZZO, Vera Lúcia. Diretrizes Curriculares Nacionais para os Cursos de Licenciatura no Brasil: da regulamentação aos Projetos Institucionais. Educação em Perspectiva, Viçosa, v. 4, n. 1, p. 15-36, jan./jun. 2013 . Disponível em: https://repositorio. ufsc.br/bitstream/handle/1 23456789/188708/0405Diretrizes\%20Curriculares\%20 Nacionais\%20para\%20os\%20Cursos\%20de\%2OLicenciatura\%20no\%20Brasil\%20-\%20 Scheibe\%20e\%20Bazzo. pdf? sequence=2\&isAllowed=y Acesso em: 13 dez. 2018.

TEZZA, Leonardo Marques. A história das disciplinas de didática do curso de pedagogia da FFC-Unesp/Marília (1963-2005). 2018. Dissertação (Mestrado em Educação) - Universidade Estadual Paulista "Júlio de Mesquita Filho" (Marilia), 2018. Disponível em: http://hdl.handle.net/1 1449/153149. Acesso em: 19 ago. 2019.

UNIVERSIDADE FEDERAL DO PARANÁ. Setor de Educação, Curso de Pedagogia. Projeto

Político Pedagógico do Curso de Pedagogia da Universidade Federal do Paraná. 1982.

UNIVERSIDADE FEDERAL DO PARANÁ. Setor de Educação, Curso de Pedagogia. Projeto Político Pedagógico do Curso de Pedagogia da Universidade Federal do Paraná. 2018. Disponível em: http://www.pedagogia.ufpr.br/ppp.html. Acesso em: 12 jan. 2019.

VEIGA, Ilma Passos de Alencastro. A prática pedagógica do professor de didática. São Paulo: Papirus, 1994.

VEIGA, Ilma Passos de Alencastro. Didática: uma retrospectiva histórica. In: VEIGA, Ilma Passos de Alencastro (Coord.). Repensando a didática. Campinas: Papirus, 2004. 
Profa. Dra. Joana Paulin Romanowski

Centro Universitário Internacional (UNINTER - Brasil) Programa de Pós-Graduação em Educação e Novas Tecnologias Pontifícia Universidade Católica do Paraná (Brasil) Grupo de Pesquisa Práxis Educativa: Dimensões e Processos. ORCID: http:/ / orcid.org/0000-000 1-7043-5534 E-mail: joana.romanowski@gmail.com

Ms. Juliana Domit Mallat Pontifícia Universidade Católica do Paraná (Brasil) Doutorando do Programa de Pós-Graduação em Educação Grupo de Pesquisa Práxis Educativa: Dimensões e Processos ORCID: https://orcid.org/0000-0003-4917-1639 E-mail: jumallał@hotmail.com Ms. Enderson Lopes Guimarães Pontifícia Universidade Católica do Paraná (Brasil) Doutorando do Programa de Pós-Graduação em Educação Grupo de Pesquisa Práxis Educativa: Dimensões e Processos ORCID: hitps:/ / orcid.org/0000-0002-1 51 8-8320 E-mail: enderson2ufpr@yahoo.com.br Recebido 28 set. 2019 Aceito 12 nov. 2019 